\title{
Üniversite Yerleşkesi İçin Yolculuk Davranış Analizi: Gazi Üniversitesi Maltepe Yerleşkesi Örneği
}

\author{
DOI: $10.26466 /$ opus.559415 \\ * \\ Hayri Ulvi* \\ * Dr, Gazi Üniversitesi, Mimarlık Fakültesi, Çankaya/Ankara/Türkiye \\ E-Posta: hayriulvi@gmail.com \\ ORCID: 0000-0003-2988-6215
}

\section{Öz}

Yolculuk davranış analizi yolculuk üreten belirli bir bölgede yolcuların ulaşım davranışlarını ölçmek amacıyla yapılmaktadır. Kentlerde ve çekim merkezleri haline gelmiş mekânlarda yolculuk davranışlarının ölçülmesi günümüzde ve gelecekte yaşanılabilecek ulaşım sorunların önlemek amacıyla yapılmaktadır.Yolculuk davranış analizinden elde edilen sonuçlara göre durum tespiti yapılmakta ve ulaşım politikalarına yön vermektedir.Kentlerin ve çekim merkezi haline gelmiş yolculuk üretebilen mekan ve alanlara yönelik ulaşım politikaları bu alanlarda ortaya çıkabilecek sorunlara karşı öneri getirmeyi hedeflemektedir. Üretilen bu politika ve geliştirilen öneriler ulaşım uygulama projelerine bir girdi sağlamaktadır.Bu çalışma kapsamında Gazi Üniversitesi Maltepe Yerleşkesinde kullanıcı kitlesi olarak öğrenciler ile akademik-idari personelin ulaşım davranışlarının anket uygulaması yoluyla ölçümlenmesi hedeflenmektedir. Bu kapsamda Gazi Üniversitesi Maltepe Yerleşkesi bütününde 28 anketör tarafindan toplam 274 kişi ile anket uygulaması yapılmıştır. Anket uygulamasından elde edilen veriler bulgular Ankara Ulaşım Ana Planı verileri ile karşılaştırılarak Gazi Üniversitesi Maltepe Yerleşkesi kullanıcılarının ulaşım davranışları değerlendirilmektir. Araştırma sonunda; Gazi Üniversitesi Maltepe Yerleşkesinin Ankara Metropoliten kenti bütününde ulaşılabilirlik ve erişilebilirlik sorunları tespit edilerek, geleceğe yönelik öneriler sunulmaktadır.

Anahtar Kelimeler: Ulaşım Davranışı, Yolculuk Analizi, Üniversite Yerleşkesi, Ankara 


\title{
A Travel Behavior Analysis for University Campus: A Case Study of Gazi University in Maltepe Campus
}

\begin{abstract}
Travel behavior analysis is carried out in order to measure the transport behavior of passengers in a specific region. Measurement of travel behaviors in places that have become centers of attraction in cities and places of attraction is carried out in order to prevent the problems of transportation in our time and in the future. transport policies for the areas are aimed at making suggestions against the problems that may arise in these areas. This policy and the proposals developed provide an input to the transportation application projects. In this study, it is aimed to measure the transportation behaviors of students and academic-administrative personnel as a user population in Gazi University Maltepe Campus by means of questionnaire application. In this context, a total of 274 people were interviewed by 28 interviewers in the Gazi University Maltepe Campus. The data obtained from the survey application are compared with the Ankara Transportation Master Plan data and the transportation behaviors of the users of Gazi University Maltepe Campus are evaluated. At the end of the research; Accessibility and accessibility problems are identified and recommendations for the future are presented in Ankara Metropolitan Municipality of Gazi University Maltepe Campus.
\end{abstract}

Keywords: $\quad$ Travel Behavior, Travel Analysis, University Campus, Ankara 


\section{Giriş}

Yerleşimler çevresinde yer alan eğitim, ticaret ve sosyo-kültürel alanlarının insanlık için bir çekim merkezi olduğu görülmektedir (Hatt, Reiss 2002, s.28). Zamanla artan nüfus ve gelişen teknoloji ile birlikte toplumların çağ 1 yakalayabilmek için eğitim ve öğretim faaliyetlerine hız verme eğiliminde olduğu görülmektedir. Bu eğilim sonucunda eğitim ve öğretim faaliyetlerinin en üst düzeyde gerçekleştiği kurumlardan birisi üniversite olarak tanımlanmaktadır. Üniversiteler toplumların gelişmesinde ve kalkınmasında öncülük eden kurumlardandır (Ataünal, 1994, s.111; Lapa ve Ardahan, 2009, s.134).

Kentleşme oranının artması, üniversiteler ile ilgili iki temel gelişme üzerinde etkilidir; birincisi kentlerin genişleyerek mevcut üniversite alanlarını içerisine alması, ikincisi yeni üniversite alanlarının kurulması şeklindedir. Kentleşmenin artmasına bağlı olarak üniversitelerin kent merkezi içerisinde kalması ve yeni üniversitelerin kentten uzak alanlarda yer seçmesi sonucu üniversitelere erişimin kısıtlanması söz konusu olabilmektedir (Arap 2007, s.13; Göçer - Göçer, 2019, s.37).

Üniversiteler yerleşkelerinde eğitimin yanı sıra sunduğu sosyo-kültürel, iş ve yurt olanaklarıyla yerleşim bölgelerinden bir trafik ve yolculuk çekmektedir(Süt, Hamurcu ve Eren, 2019, s.10). Kampüse personel ve öğrenci yolculuklarının yanı sıra kampüs ihtiyaçları doğrultusunda (kargo, servis) çeşitli araç ve yolculuk türlerinde çekim oluşturmaktadır. Üniversitelerin kendilerine özgü trafik oluşturması üniversitenin yer seçtiği bölgeyi ulaşım anlamında olumlu veya olumsuz etkileyebilmekte ve ulaşımda aksaklıklara neden olmaktadır(P. Fernandes, Macedo ve Coelho 2019, s.1).Ulaşımda yaşanan bu aksama ve kısıtlanma yerel yönetimler tarafından trafik etüdü veya ulaşım ana planları yaptırılarak çözülmeye çalışılmaktadır. Ulaşım ana planları ile ekonomik ve sosyal gelişmenin ihtiyaç duyduğu gerekli altyapı sağlayarak, ulaşım türleri arasında dengenin sağlanması amaçlanmaktadır. Ulaşım ana planları ulaşımı ekonomik ve konforlu kılmak için tespitler yapmakta ve çözüm önerileri getirmektedir (Önder ve Akdemir,2019, s.25).

Bu araştırmanın amacl; Gazi Üniversitesi Maltepe Yerleşkesinde kullanıcı kitlesi olarak öğrenciler ile akademik-idari personelin yolculuk davranışlarının ölçülerek, Ankara Metropoliten Kenti yolculuk verileri ile 
karşılaştırmasıdır. Bu çerçevede örneklem alan olarak belirlenen Gazi Üniversitesi Maltepe Yerleşkesinde belirlenen noktalarda yaya, toplu taşım ve araç ile erişim sağlayan kullanıcı kitlesi üzerinde anket uygulaması gerçekleştirilmiştir.

Araştırmanın; Ankara Metropoliten bütününde üniversite yerleşkesi odaklı güncel ulaşılabilirlik ve erişilebilirlik sorunlarının tespitinin, ötesinde üniversite yerleşkelerine ilişkin gelecekteki olası ulaşım ve erişim sorunlarının çözümüne yönelik araştırma ve uygulamalara katkı koyabileceği düşünülmektedir.

\section{Literatür Taraması}

Üniversite yerleşkelerini kullanan öğrenci ve personelin ulaşıma ilişkin yolculuk davranışlarının ölçülmesinin geçmişten günümüze kadar birçok çalışmada konu olarak yer almaktadır. Özellikle ABD' deki plancılar son on yılda kampüs niteliklerini tahrip etmeden erişimin sağlanması mücadelesi verilmektedir (Bustillos vd. 2011). Son yıllarda artan nüfus ile birlikte yerleşkelere olan talebin artması yerleşkelere ulaşımda alternatif ulaşım türlerinin (mod) ortaya çıkmasını zorunlu kılmaktadır

Üniversite yerleşkelerine erişebilmek için yolculuk davranışının ölçülmesi kapsamında dünya örneklerine bakıldığında sürdürülebilir farklı ulaşım türlerini ele alan çalışmalardan biri Barselona kenti çalışmasıdır. Yapılan çalışma ile Autonomous University of Barcelona üniversitesinin Barselona metropoliten alanında yer alan nispeten seyrek nüfuslu bir alanda yer alan yerleşke kullanıcılarının yolculuk davranışları ölçülmektedir. Çalışma sonucunda UAB yerleşkesine ulaşım için kullanılan yolculuk talep yönetimi stratejilerinde yaşanan aksaklık ve zorluklara 1şık tutulmaktadır ( Miralles-Guasch ve Domene 2010, s.455).

Autonomous University of Barcelona (UAB) üniversitesinin yer aldığ 1 banliyö alanı üniversitenin etkisi ile günlük 220.000 yolculuk oluşturmaktadır. Elde edilen veriler ışığında yerleşkeye gelen öğrenci ve çalışan personelin \%41'nin toplu taşıma aracı kullanmasına rağmen hala 15.000 kişi özel aracı ile yolculuk yaptığı sonucuna varıldığı ifade edilmektedir. Çalışma kapsamında üniversiteye olan yolculuklar için alternatif ulaşım modu önerisinde bulunulmaktadır (Miralles-Guasch ve Domene 2010, s.457). 
Diğer bir çalışmada ise üniversite kampüslerini sürdürülebilir mekânlar yapmak için bisiklet ve yaya planlama açısından neler yapılabileceği vurgulanmaktadır. Çalışma kapsamında 8 ayrı üniversite kampüsünde anketler yapıldığı görülmektedir. Anket sonuçlarından çıkan çıkarımlara göre kampüslerde motorsuz taşımacılığın ve alternatif ulaşım modlarının gerekliliği vurgulanmaktadır (Balsas,2003, s.40).

Malezya Teknoloji Üniversitesi (UTM) kampüsünde yapılan bir çalışmada modern üniversitelerin kampüs sokaklarının yaya dostu olması gerekliliğinden bahsedilmektedir. Çalışmada aynı zamanda kampüs sokaklarında ve yayalara yönelik altyapının değerlendirilmesinde bir önlem olan kampüsler için yaya hizmet düzeyini Pedestrian Level of Science (PLOS) tanitmaktadır (Asadi-Shekari vd. 2014, s.176).

Pekin Havacılık ve Uzay Üniversitesi yerleşkesinde otopark sorununa ilişkin bir çalışma ifade edilmektedir. Bu çalı̧̧maya göre son yıllarda artan araç sahipliliği ile beraber üniversite çalışanları da ikamet ettikleri yerleri üniversite yerleşkesinden uzakta yer seçme eğiliminde olduğundan bahsedilmektedir. Artan motorlu taşıtların doğal sonucu olarak üniversite kampüslerindeki otoparkların yetersiz kaldığı vurgulanmaktadır. Çalışma kapsamında araç sayımı, araç park süresi ve otopark sayımı gibi istatiksel bilgiler toplanıp işlendiği belirtilmektedir (Shang vd. 2007, s.139).

Kampüs içi modelleme çalışmasına örnek olarak ABD üniversitesiler kampüs içi otopark ve trafik modellemesi verilebilmektedir. Çalışmada kampüs içi zonlar ve sayım noktaları belirlenerek bu noktalarda sayım yapıldığ 1 ve çıkan sonuçların PTV Visum gibi programlarda değerlendirildiği belirtilmektedir (Bustillos vd. 2011, s.188).

İstanbul'da yer alan, Koç Üniversitesi Sarıyer Kampüsü (kent dışı kampüs), Bahçeşehir Üniversitesi Beşiktaş Kampüsü (kent üniversitesi), Yıldız Teknik Üniversitesi Yıldız Merkez Kampüs (kent içi kampüs) alanlarında anket yöntemi ile öğrencilerin sosyal mekân kullanımları ve bu mekânlara erişim davranışlarını ölçen bir çalışma olarak ifade edilmektedir. Çalışma kapsamında kampüs alanları kent içi ve kent dışı yerleşkeler olarak iki ayrı kategoride incelenmektedir (Erçevik, 2008, s.3).

Orta Doğu Teknik Üniversitesi Ankara yerleşkesinde kampüs kullanıcılarının yolculuk davranışlarını ölçmek için bir çalışmanın yapıldığı ifade edilmektedir. Geleneksel anket yaklaşımı yerine kampüs girişi kapıla- 
rında yer alan radyo frekansı ile tanımlama sistemi (RFID) sistemi ile kampüs kullanıcılarının yolculuk davranışları ölçülmesi amaçlanmaktadır. Akademik personel, idari personel ve öğrencilerin yolculuk davranışları ayrı ayrı değerlendirildiği bir çalışmadır (Altıntaşı ve Yaman 2016, s.171). İncelenen çalışmaların ortak noktası kampüs kullanıcılarının yolculuk davranışlarını ölçerek günümüzde ve gelecekteki sorunları tespit etmek ve öneriler getirmektir. Uygulama-araştırma yöntemleri ve ülkelere göre farklılık göstermesine rağmen kampüse ulaşımda her bir çalışma tespit ve öneri bulunmaktadır. Çalışmalarda ortak sorun araç sahipliliğin artması ve yoğun trafik olarak görülmektedir. Her çalışma alternatif ulaşım sistemlerinin ve yaya yolculuğunun artırılması önerisinde bulunmaktadır. İstanbul da yer alan Koç ve Bahçeşehir Üniversitesini kapsayan çalışma diğer çalışmalardan ayrılmaktadır. Bu çalışma daha çok kampüs içerisindeki sosyal mekân alan kullanımlarını ve mekânlara erişimi incelemektedir. Diğer çalışmalarda ise kampüs kullanıcılarının genel yolculuk ve erişim davranışları ölçülmekte, öneriler getirilmektedir. Yapılan çalışmalarda geleneksel anket yöntemi kullanılmasının yanı sıra RFID sistemi gibi araç okuma sistemlerinden yararlanılarak da veri elde edilebildiği görülmektedir.

\section{Araştırma Kapsamı ve Yöntemi}

Araştırmanın kapsamı 1966 yılında Ankara Devlet Mühendislik ve Mimarlık Akademisi olarak kurulan, 1982 yılında ise Gazi Üniversitesi adını alan devlet üniversitesinin, 2 (iki) fakülte ve 5 (beş) uygulama araştırma merkezi ile bir kütüphanenin bulunduğu yaklaşı 21,184 $\mathrm{m} 2$ büyüklükteki Maltepe Yerleşkesidir.

Harita 1 incelendiğinde Ankara metropoliten alanda Gazi Üniversitesi Maltepe Yerleşkesi Çankaya süper zonunda yer almaktadır. Yerleşke Ankara metropoliten alanda merkezi bir konumda yer almaktadır. Ulus, Sihhiye ve Kızılay Meydanı gibi önemli çekim merkezlerine yürüme mesafesindedir. Kampüsün kuzeyinde YHT garı, batısında Tur Oto, güneyinde GMK Bulvarı ve doğusunda Opet-Maya Göz Hastanesi yer almaktadır. 


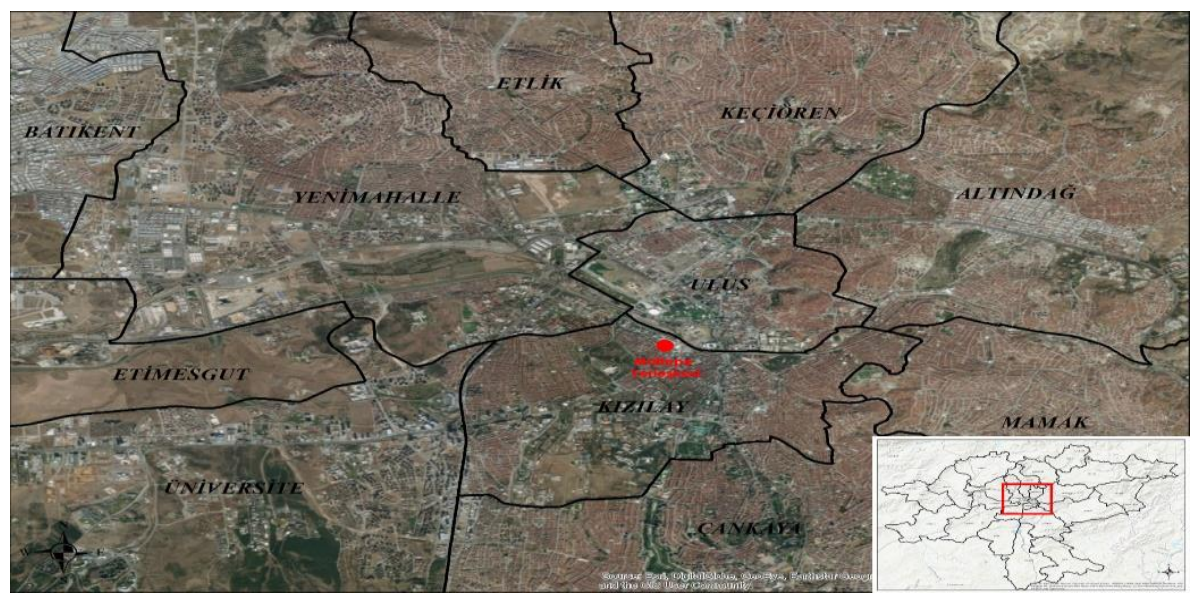

Şekil 1. Ankara Metropoliten Süper Zonlarn

Araştırma; Gazi Üniversitesi Maltepe Yerleşkesi kullanıcılarının ulaşım davranışlarının tespitine yönelik olarak yüz yüze anket yönteminden elde edilen bulguların, Ankara Ulaşım Master Planı verileri ile karşılaştırmalı yorumlanmasına dayanmaktadir.

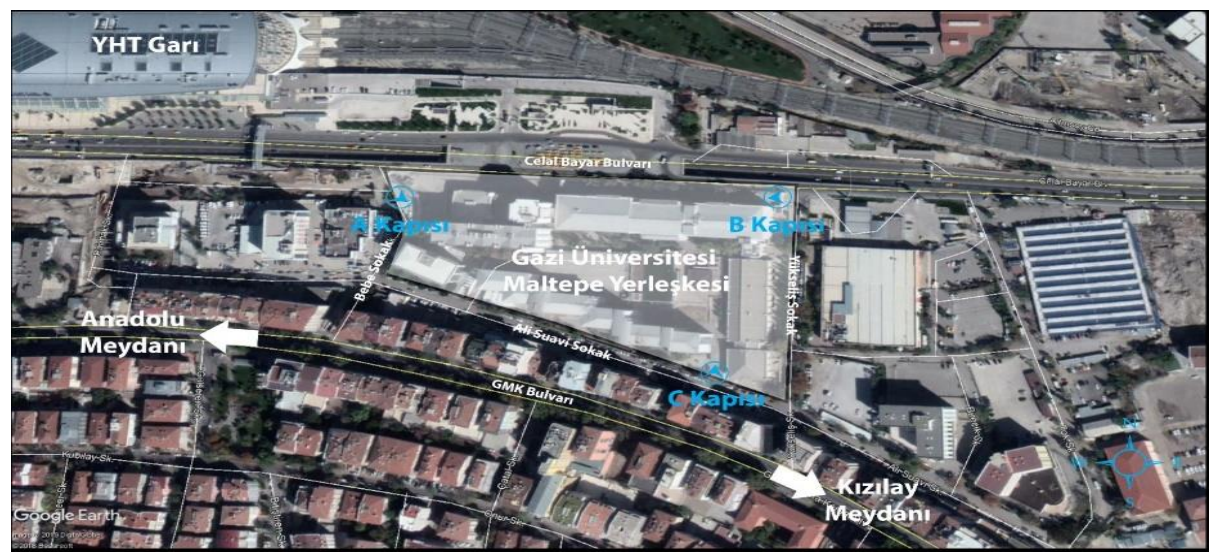

Şekil 2. Gazi Üniversitesi Maltepe Yerleşkesi

Bu çerçevede, 17.12.2018-23.12.2018 tarihleri arasında Gazi Üniversitesi Maltepe Yerleşkesi bütününde 28 anketör tarafından öğrenci, akademik ve idari personel olmak üzere toplam 274 kişi ile anket uygulaması gerçekleştirilmiştir. Anket çalışması kapsamında ankete katılan kampüs 
kullanıcılarına; cinsiyet, yaş, öğrenim görülen bölüm/çalışılan bölüm, araç sahiplilik durumu, araç park yeri tercihi, kullanılan ulaşım türü, yolculuk süresi gibi sorular yöneltilmiştir. Anket sonuçları istatistiksel ve grafiksel ifadelere dönüştürülerek, 2038 Ankara Ulaşım Master Planı ulaşım ve yolculuk davranışlarına ilişkin kent bütünü sayısal verileri ile karşılaştırılmiştır.

\section{Bulgular}

Gazi Üniversitesi Maltepe Yerleşkesi kullanıcılarının ulaşım davranışlarının belirlenmesine yönelik anket uygulanan toplam 274 kişinin \%77 bölümü öğrenci, \%7,4 bölümü akademik personel, $\% 4,4$ bölümü idari personel ve \%10,9 bölümü ise ziyaretçi kitlesidir.

Anket çalışmasına katılan kampüs kullanıcılarının \%80 bölümü 14-27 yaş , \%13,8 bölümü 27-40 yaş ve $\% 5,5$ bölümü 40 yaş ve üstü olan yaş gruplarıdır. Veriler incelendiğinde anket uygulanan kampüs kullanıcılarının büyük bir bölümünün gençler olduğu görülmektedir.

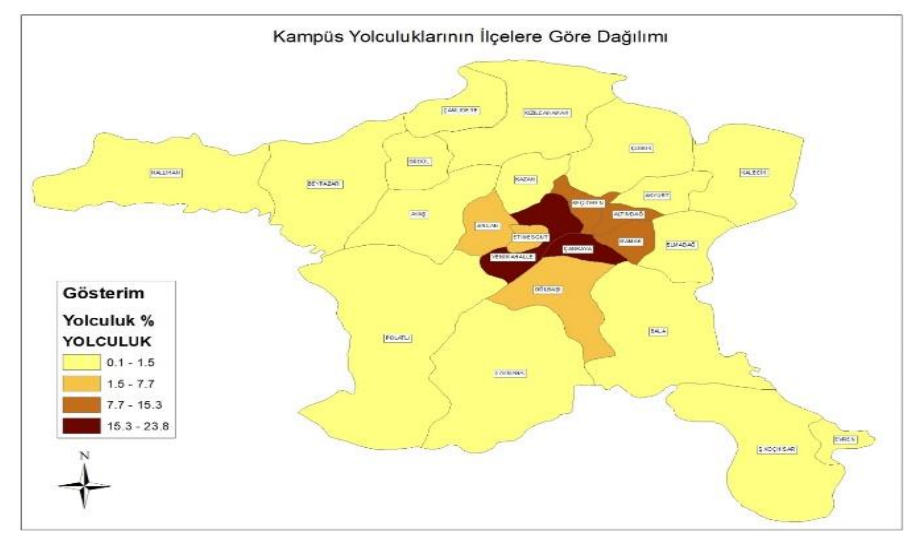

Şekil 3. İlçelere Göre Yolculuk Dağıllımı

Gazi Üniversitesi Maltepe Yerleşkesi Ankara'nın farklı ilçelerinden yolculuk çekmektedir. Maltepe Yerleşkesi ilçelere göre yolculuk dağılımı Şekil 4 'te gösterilmektedir. Anket uygulananlardan büyük bir bölümü Çankaya ve Yenimahalle ilçelerinden geldiği görülmektedir. En az ise Kazan ve Ulus ilçeleri olduğu görülmektedir. 


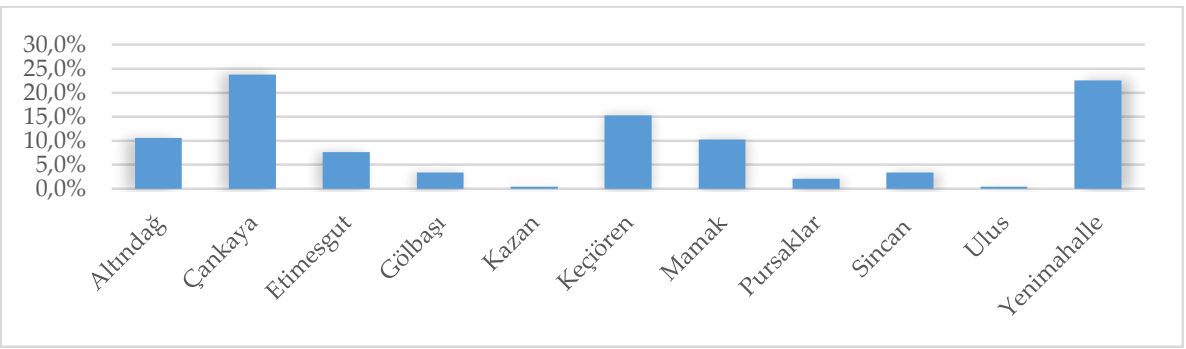

Şekil 4. İlçelere Göre Yolculuk Dağılımı

Anket çalışmasından elde edilen veriler, araç sahiplilik durumu, kampüs araç park yeri tercihi, kampüse gelirken kullanılan ulaşım türü, kampüse ulaşma süresi göstergeleri olmak üzere 4 (dört) başlık altında ele alınarak, 2038 Ankara Ulaşım Ana Planı verileri bağlamında yorumlu değerlendirilmiştir.

Ankete katılan kampüs kullanıcıların araç sahiplilik durumu Tablo 1 de gösterilmektedir. Ankete katılan kampüs kullanıcıların taşıt sahipliliği incelendiğinde \%19'luk kısım taşıtı olduğunu belirtirken \%81'lik büyük çoğunluğun kendine ait taşıtı bulunmamaktadır.

Taşıt sahiplilik durumunun düşük çıkması kampüse ulaşımda toplu taşıma ya da alternatif ulaşım türlerinin kullanıldığını ortaya koymaktadır. Özel araç kullanımının düşük olması hem çevre için hem de kampüs içi ve dışı araç trafiği için olumlu bir gelişmedir. Üniversite kampüsleri gibi büyük kamusal mekânlara ulaşımda toplu taşıma ve alternatif ulaşım türlerinin kullanılmalıdır.

Tablo 1. Taşıt Sahiplilik Durumu

\begin{tabular}{llll}
\hline & Taşıtı Var & Taşıtı Yok & Belirtilmemiş \\
\hline $\begin{array}{l}\text { Yerleşke Taşıt } \\
\text { Sahiplilik Durumu }\end{array}$ & $19 \%$ & $81 \%$ & \\
\hline $\begin{array}{l}\text { Ankara Taşıt } \\
\text { Sahiplilik Durumu }\end{array}$ & $55.4 \%$ & $44.4 \%$ & $0.2 \%$ \\
\hline
\end{tabular}

2038 Ankara Ulaşım Ana Planı hane halkı taşıt sahipliliği verisi tablo 1 de yer almaktadır. AUAP verisine göre Ankaralıların \%55,4'ünün taşıta sahip olduğu, \%44,4'ünün ise taşıta sahip olmadığı belirtilmektedir (KUTEM a, 2014, s.20). 
Taşıt kullanımının artmasına bağlı olarak trafik sıkışıklığı ve hava kirliliği günümüz kentlerinin önemli sorunları arasında yer almaktadır (Babalik-Sutcliffe, 2013, s.416). Ankara da ikamet eden vatandaşların yarısından fazlasının taşıtının olması Ankara kentinde de trafik sıkışıklığının ve hava kirliliği gibi sorunlarla günümüzde ya da gelecekte karşılaşılması muhtemeldir.

Gazi Üniversitesi Maltepe yerleşkesinde yapılan çalışma ile AUAP yer alan araç sahiplilik durumu farklılık göstermektedir. Üniversite de yap1lan çalışmada taşıt sahipliliği düşük çıkarken AUAP verilerinde taşıt sahipliliği yüksek çıkmaktadır. Üniversite kampüs kullanıcılarının büyük çoğunluğunun öğrenci olması taşıt sahiplilik oranını düşürmede etkili olmaktadır. Üniversite kampüsünün ulaşım bağlantılarına yakınlığı ve kampüs çevresinde yeterince konut alanının varlığı taşıt sahipliliğine gerek duyulmamış olması başka bir ihtimal olarak değerlendirilebilir.

Ankete katılan kampüs kullanıcıların taşıt park yerleri öncelik sıralamaları Tablo 2 de gösterilmiştir. Aracı olan bireylere kampüse geldiklerinde araçlarını park ettikleri yerlerin kullanım sıklıklarının sıralanması istenmektedir. Tercihlere bakıldığında otopark tercihlerinin birbirine çok yakın olduğu görülmektedir. Kampüs İçi Kapalı Otoparkın en çok tercih edilen otopark yeri olduğu görülmektedir.

Tablo 2. Yerleşke Taşıt Park Yeri Tercihi

\begin{tabular}{llll}
\hline $\begin{array}{c}\text { Kampüs İçi Yer } \\
\text { Üstü Park Alanı }\end{array}$ & $\begin{array}{l}\text { Kampüs İçi } \\
\text { Kapalı Otopark }\end{array}$ & $\begin{array}{l}\text { Kampüs Dışı } \\
\text { Yol Üzeri Park }\end{array}$ & $\begin{array}{l}\text { Kampüs } \\
\text { Dışı Otopark }\end{array}$ \\
\hline $\mathbf{2 5 . 3 0} \%$ & $23.80 \%$ & $25.70 \%$ & $25.10 \%$ \\
\hline
\end{tabular}

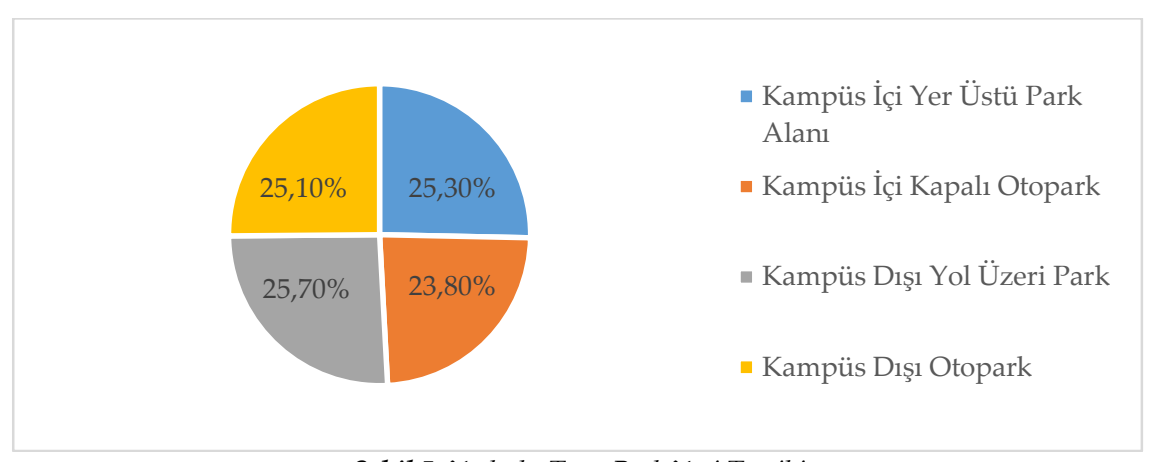

Şekil 5. Yerleşke Taşıt Park Yeri Tercihi 
Taşıt park yerleri öncelik sıralamalarına bakıldığında kullanıcıların büyük çoğunluğunun taşıtlarını kampüs içerisine değil, kampüs dışına park ettikleri görülmektedir. Öğrenci taşıtlarının kampüs içerisine alınmaması kampüs dışı parklanmayı tetiklemektedir.

Tablo 3. Ankara Taşıt Park Yeri Tercihi

\begin{tabular}{llll}
\hline & Yol Boyu Otopark & Açık Otopark & Katlı Otopark \\
\hline $\begin{array}{l}\text { Ankara Araç Park } \\
\text { Yeri Tercihi }\end{array}$ & $47.5 \%$ & $16.3 \%$ & $36.2 \%$ \\
\hline
\end{tabular}

\section{Ankara Taşıt Park Yeri Tercihi}

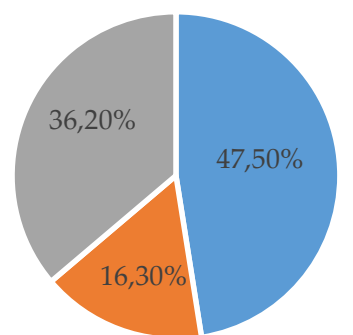

- Yol Boyu Otopark

- Açık Otopark

- Katlı Otopark

Şekil 6. Ankara Taşıt Park Yeri Tercihi

2038 Ankara Ulaşım Ana Planı taşıt park yeri tercihi Tablo 3 de yer almaktadır. Tablo incelendiğinde Ankaralıların; \%47,5'inin Yol boyu otoparkı, 36,2 sinin Katlı otoparkı, 16,3'ü ise Açık otoparkı kullanmaktadırlar (KUTEM, 2014, s. 35).

Üniversite de yapılan çalışmadan çıkan sonuç ile paralellik göstermektedir. Üniversite kampüs alan çalışmasında da kampüs dışı otopark ve kampüs dışı yol üstü otopark en çok tercih edilen otopark alanları olarak çıktığı görülmektedir. Otopark alanlarının yetersiz, erişebilir olmaması ve otoparklarda ortaya çıkan güvenlik sorunları açı otoparkların tercih edilebilirliğini düşürmektedir. LPG kullanan taşıtların otoparka alınmaması ve otoparkların yaygın olmaması kapalı ve katlı otopark seçiminin yol boyu otoparka göre daha az tercih edilme sebepleri olarak düşünülebilir.

Ankete katılan kampüs kullanıcılarının kampüse gelirken kullandıkları ulaşım türleri Tablo 4'de gösterilmektedir. 
Kampüse gelirken kullanılan ulaşım türleri incelendiğinde en çok tercih edilen modların sırasıyla Otobüs, Ankaray, Dolmuş, Metro, Yaya olduğu görülmektedir. En az tercih edilen ulaşım türlerinin ise sırasıyla Bisiklet, Banliyö, Taksi olduğu görülmektedir. Toplu taşımada en çok tercih edilen ulaşım araçları ise otobüs, dolmuş, Ankaray ve metrodur. Öğrencilerin Maltepe civarında yurt ve evlerden okula gidip gelmede yaya yolculuk yapmalarından dolayı yaya ulaşımı da toplu taşıma kadar önemli bir yer tutmaktadir.

\section{Tablo 4. Kullanılan Ulaşım Türü}

\begin{tabular}{lcc}
\hline & $\begin{array}{c}\text { Ankara Metropoliten Kenti } \\
\text { Ulaşım Türü Dağılımı }\end{array}$ & Yerleşke Ulaşım Türü Dağılımı \\
\hline Yaya & $27.91 \%$ & $11.80 \%$ \\
Özel Oto & $21.69 \%$ & $9.80 \%$ \\
Taksi & $1.00 \%$ & $4.20 \%$ \\
Servis Aracı & $8.66 \%$ & $0 \%$ \\
Minibüs & $9.99 \%$ & $15.50 \%$ \\
Otobüs & $24.67 \%$ & $23.90 \%$ \\
Motosiklet & $0.07 \%$ & $0 \%$ \\
Bisiklet & $0.08 \%$ & $1.20 \%$ \\
Metro & $3.56 \%$ & $12.50 \%$ \\
\hline
\end{tabular}

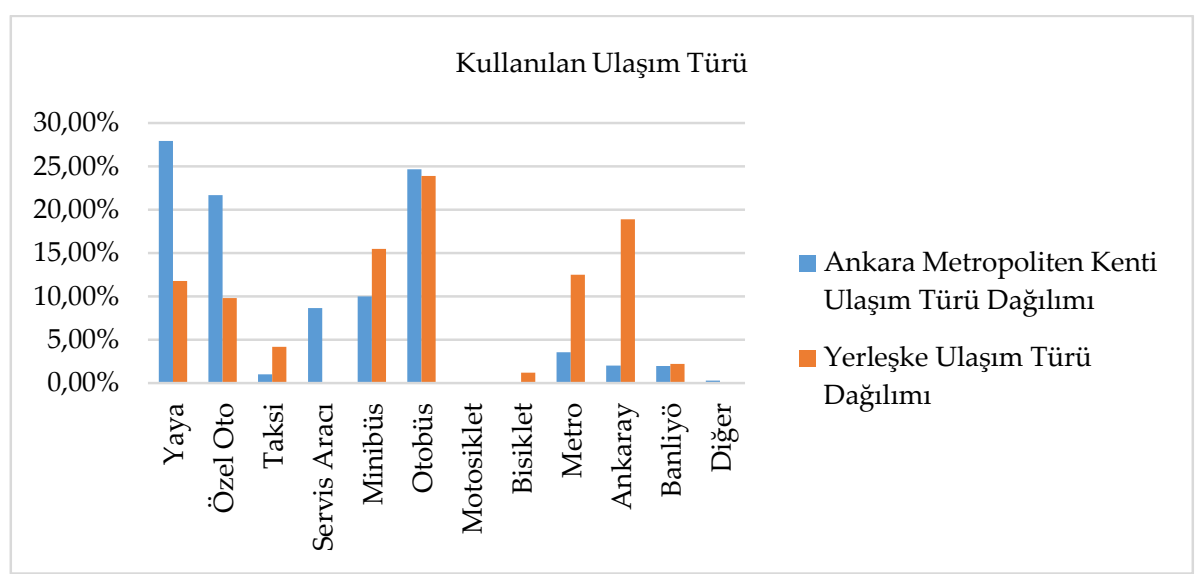

Şekil 7. Kullanılan Ulaşım Türü

2038 Ankara Ulaşım Ana Planı hane halkı ulaşım türü dağılımı Tablo 4 de yer almaktadır. Grafik incelendiğinde Ankaralıların yolculuk yaptıklarında \%27,91 ile yaya yolculuğunu tercih etmektedirler. Toplu taşıma 
araçlarında ise en çok \%21,67 ile otobüs tercih edilmektedir. Özel oto yolculuğu ise toplam \%21,69 ile dikkat çeken bir orana sahiptir (KUTEM c, 2014, s.101).

AUAP ve Üniversite kampüs alan çalışması verileri incelendiğinde yolculuklarda kullanılan ulaşım türü dağılımın da benzerlik göstermektedir. Ankara genelinde raylı sistemin il geneline hizmet vermemesi otobüs ve minibüs kullanımını artırmaktadır. AUAP verilerinde en çok yaya ve otobüs kullanımı en çok tercih edilirken, üniversite kampüs alan çalışma verilerinde otobüs ve Ankaray tercih edilmektedir. Üniversite kampüs alanının karayolu ulaşım bağlantılarının merkezinde olması otobüs tercihini artırmaktadır. Ankaray kullanımı ise kampüs alanına yürüme mesafesinde iki Ankaray istasyonun (Maltepe ve Demirtepe) varlığı kampüse ulaşımda daha çok tercih edilme sebebi olarak gösterilmektedir (KUTEM, 2014, s.101).

Ankete katılan kampüs kullanıcılarının konuttan kampüse ulaşma sürelerin Tablo 5'de gösterilmektedir. Grafiğe bakıldığında; \%36'lık kısım kampüse 16-30 dk, \%25'lik kısım kampüse 31-45 dk, \%17'lik kısım kampüse 46-60 dk, \%16'lik kısım ise kampüse 0-15 dk, \%5'lik ise kampüse ulaşma süresinin $61 \mathrm{dk}$ ve üzeri sürdüğünü ifade etmektedir.

Tablo 5. Yolculuk Sürelerinin Dă̆ılımı

\begin{tabular}{lrrrrr}
\hline & $\mathbf{0 - 1 5} \mathbf{~ D k}$ & $\mathbf{1 6 - 3 0 ~ D k}$ & $\mathbf{3 1 - 4 5 ~ D k}$ & $\mathbf{4 6 - 6 0 ~ D k}$ & $\mathbf{6 1 +} \mathbf{D k}$ \\
\hline Yerleşke Ulaşım Süresi & $16 \%$ & $36 \%$ & $25 \%$ & $17 \%$ & $6 \%$ \\
Ankara Ulaşım Süresi & $30.66 \%$ & $34.33 \%$ & $11.35 \%$ & $14.76 \%$ & $8.9 \%$ \\
\hline
\end{tabular}

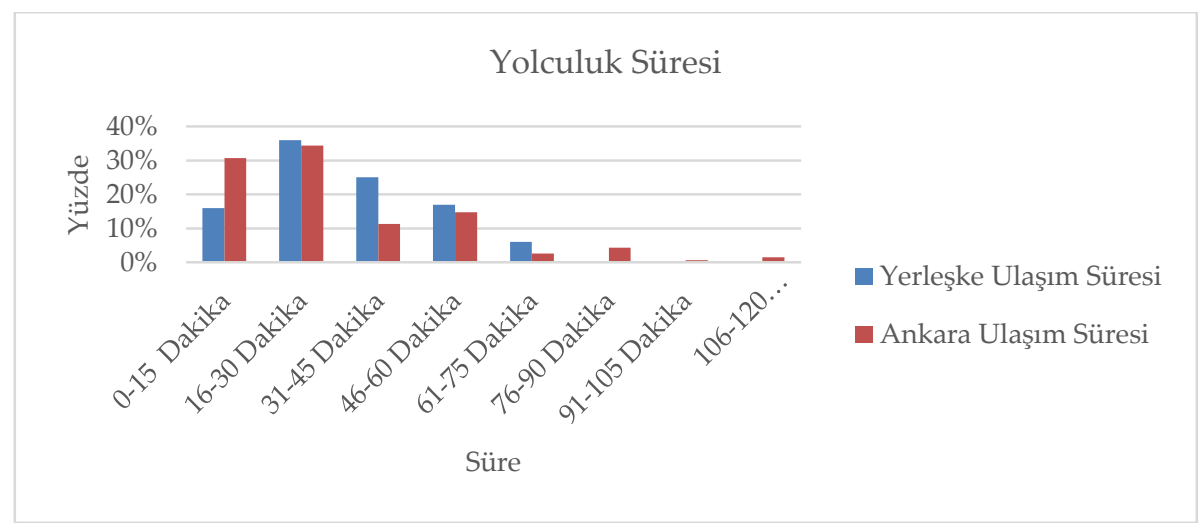

Şekil 8. Yolculuk Sürelerinin Dă̆ılımı 
Ankara 45 dakikalık yolculukların öne çıktığı bir kenttir. Nitekim grafik incelendiğinde tüm yolculukların \%75'e yakını 45 dakikanın altında gerçekleştiği görülmektedir(KUTEM a,2014, s.113). Daha uzun yolculukların trafik koşullarından etkilendiği ileri sürülebilir. Yolculuğun 45 dakikadan daha uzun sürmesinin bir diğer nedeni ise lastik tekerlekli yolcu taşımacılığıdır. Uzun güzergâh ve durak sayısının çokluğu bir araya gelince gün içerisindeki kimi zamanlarda genel trafik ile birlikte işleyen toplu taşımanın görece uzun yolculuk süreleri üretmeleri mümkün olabilmektedir. AUAP ve Üniversite kampüs alan çalışması verileri incelendiğinde yolculuk süreleri paralellik göstermektedir. Kampüse erişimde büyük çoğunluğun yolculuk süresi 45 dakikadan az sürdüğü görülmektedir.

\section{Sonuçlar}

$\mathrm{Bu}$ araştırmada geleneksel anket yöntemi kullanılarak Ankara kent merkezinde yer alan Gazi Üniversitesi Maltepe Yerleşkesi kampüs kullanıc1larına yöneltilen sorular ve bu sorulara alınan cevapların yorumlanması ve AUAP verileri ile karşılaştırılması yer almaktadır.

Kampüs kullanıcılarına yöneltilen 4 (dört) sorudan alınan cevaplar AUAP hane halkı araştırma verileri ile karşılaştırılması sonucu alınan cevaplara göre; Araç Park Yeri Tercihinin, Kullanılan Ulaşım Türünün ve Yolculuk Süresinin paralellik gösterdiği görülmektedir.

Taşıt Sahiplilik Durumu : AUAP ile üniversite anket çalışmasında farklılık göstermektedir. Kampüs kullanıcılarının önemli bir kısmının öğrenci olması araç sahiplilik durumunu düşürmektedir. Araç sahiplilik oranın düşük olması kampüse ulaşımda toplu taşıma ve yaya yolculuğunun daha çok kullanıldığını göstermektedir.

Taşıt Park Yeri Tercihi: Araçları ile kampüse gelen kampüs kullanıcılarının büyük bir kısmı aracını kampüs dışına bıraktıklarını belirtmektedirler. AUAP hane halkı verilerine göre ise Ankaralıların büyük bir kısmının yol üstü otoparkı kullandıkları görülmektedir. Yol üstü otoparklar açık ve kapalı otoparkların yetersiz olmasından dolayı ortaya çıktığı söylenebilir. Üniversite kampüs içi otoparka personel harici araç alınmaması kampüs 
dışı parklanmayı artırmaktadır. Kampüs dışında açık otopark bulunmaktadır. Ancak kampüs dışına park eden kampüs kullanıcıları Ankaralılar gibi yol üstü parklanmayı daha çok tercih etmektedirler. Yol üstü parklanma kontrolsüz yapıldığında trafik sıkışıklığına ve kazalara neden olmaktadır. Kampüs dışı parklanma daha çok GMK Bulvarı ve yan yolları üzerine yapılmaktadır. Kontrolsüz bu parklanma sabah ve akşam saatlerinde tıkanıklığa ve trafiğe neden olmaktadır.

Kullanılan Ulaşım Türü: Kullanılan ulaşım türleri incelendiğinde AUAP hane halkı verileri ve kampüs anket çalışmasının örtüştügü görülmektedir. Ankara da kısa mesafelerde insanlar daha çok yaya olarak yolculuk yaptıkları belirtilmektedir. Toplu taşımada ise en çok lastik tekerlekli sistemler tercih edilmektedir. Mevcut raylı sistem ağının kentin bütününe erişmemesi otobüs ve minibüs taşımacılığını ön plana çıkarmakta ve daha çok tercih edilmektedir. Üniversite kampüsü ise Ankara ile benzer bir davranış sergilemekle beraber raylı sistemlerin kullanılması kısmında ayrışmaktadır. Kampüs kullanıcıları metro ve Ankaray'ı Ankaralılara oranla yolculuk tercih sirasında daha ön planda tutmaktadır. Metronun özelikle Ankaray'ın kampüse yürüme mesafesinde olması bu tercihi etkilemektedir. Buna rağmen kampüs kullanıcıları da Ankaralılar gibi lastik tekerlekli taşımayı daha fazla tercih etmektedir.

Yolculuk Süresi : Ankara da ortalama yolculuk süresi 45 dakika olarak belirtilmektedir. AUAP verileri incelendiğinde tüm yolculukların \%75'e yakını 45 dakikanın altında gerçekleştiği görülmektedir. Daha uzun yolculukların kat edilen mesafe ve trafik ile açıklanmaktadır. Ayrıca lastik tekerlekli sistemlerde hat uzunluğunun ve durak sayısının fazlalığı yolculuk süresini etkilemektedir. Üniversite kampüs araştırması incelendiğinde Ankara ile benzer bir ulaşım süresi ortaya çıtığı görülmektedir. Kampüse ulaşımda \%71'lik kısım kampüse 15-45 dakika aralığında kampüse ulaştıklarını belirtmektedirler. Kampüsten ortalama 45 dakika sürede Ankara'nın büyük bir kısmına ulaşılabileceği görülmektedir. Kampüsün kent merkezinde yer alması, Sıhhiye-Kızılay gibi aktarma noktalarına yakınlığı ve metro-Ankaray-Banliyö gibi raylı sistemlerin durak noktalarına yürüme mesafesinde yer alması kampüse ulaşımı kolay kılmakta, yolculuk süresini kısaltmaktadır. 
Kent merkezinde yer alan bir üniversite kampüsü (Gazi Üniversitesi Maltepe Yerleşkesi) ile Ankara kentinin genel yolculuk karakteristiklerinin büyük oranda benzeştiği görülmektedir. Aynı zamanda kentin yaşadığı ulaşım sorunlarını da yansıttığı söylenebilmektedir.

Ankara kentinde yaşanan yol boyu parklanma sorunu kampüs parklanmasında da görülmektedir. Yol boyu parklanma sorunun ve kampüs dışı parklanma kampüs içi otopark düzenlemeleri çözülebilmektedir. Öğrenci otoparkı için ayrı bir otopark alanı yapılmalıdır. Ziyaretçi otoparkı genişletilmeli, mevcut otopark tekrardan düzenlenmeli ve engelli bireyler düşünülerek otopark düzenlemeleri yapılmalıdır.

Özel araç kullanımı Ankara kenti için ilerleyen yıllarda sorun oluşturabilecek bir konu iken kampüs kullanıcılarının özel araç kullanımını çok fazla tercih etmemesi nedeni ile şimdilik sorun oluşturmamaktadır. Ancak trafikte yaşanabilecek aksaklıkları önlemek, kampüste yaşanabilecek otopark sorununa ve çevre kirliliğine engel olmak için özel araç yerine toplu taşıma kullanımı özendirmelidir. "Park et devam et" gibi sistemler ile özel araçların kent merkezine girişleri engellenebilmekte ve kentsel alanlarda özel araç girişlerine ücretlendirme ile araç kullanımını azaltılabilmektedir (Önder ve Kaplan, s.139). Bu bağlamda kampüs içi otopark ücretlendirilmesi özel araç kullanımını düşürmek için kullanılabilir bir yöntem olabilmektedir. Ayrıca konferanslar ve idari uygulamalar ile kampüs içi özel araç kullanımı azaltılmalıdır (Kös, 2015, s.2).

Tespit edilen bulgular, sorun ve öneriler Gazi Üniversitesi Maltepe Yerleşkesinin ulaşım ve erişim konusunda günümüzdeki durumunu ve gelecekte oluşabilecek sorunları önlemede önemli bir basamak olacağı düşünülmektedir. 


\title{
EXTENDED ABSTRACT
}

\section{A Travel Behavior Analysis for University Campus: A Case Study of Gazi University in Maltepe Campus}

\author{
Hayri Ulvi
}

Gazi University

Education, trade and socio-cultural areas around residential areas are seen as a center of attraction for humanity. Together with the increasing population and developing technology, it is seen that societies have accelerated their educational activities. As a result of this trend, universities have emerged as the institutions that have become the top level education institutions. Universities prioritize the development and development of societies and countries. With the increase in urbanization and population ratio, universities remained in the city center. The newly established universities are located in remote areas. Access to universities that are located in remote areas and which are within the density of the city center is restricted.

Universities do not only provide education services, but they also take various journeys with socio-cultural activities, work offices and dormitories. Apart from the students and staff, campuses also attract various vehicles and trips to the campus. Universities affect transportation positively and negatively in the regions where they are established. These negativities cause disruptions in transportation. These problems in the city are tried to be solved by local governments by making a traffic survey or transportation master plan.

Universities do not only provide education services, but they also take various journeys with socio-cultural activities, work offices and dormitories. Apart from the students and staff, campuses also attract various vehicles and trips to the campus. Universities affect transportation positively and negatively in the regions where they are established. These negativities cause disruptions in transportation. These problems in the city are tried to be solved by local governments by making a traffic survey or 
transportation master plan. Measuring the travel behavior of students and staff using university campuses has been the subject of many studies and research from past to present. Planners in the United States, in particular, have been trying to offer suggestions for transportation in the last decade without destroying campuses.

In order to reach the university campuses, one of the studies on the different types of transportation is the study of the city of Barcelona. The travel behaviors are measured in a region with a relatively sparsely populated Autonomous University of Barcelona. As a result of the study, Autonomous draws attention to the problems and difficulties in demand and management strategies used to reach the University of Barcelona. Alternative transportation modes are offered to the Autonomous University of Barcelona, which is situated in an area of 220,000 trips per day.

In another study, it is observed that pedestrian and cycling activities are carried out to make university campus venues sustainable. Within the scope of the study, 8 different university campuses were surveyed by survey method. In a study on the campus of the University of Technology Malaysia (UTM), it is mentioned that modern universities should be pedestrian friendly. It is recommended to promote and promote pedestrian access through the study. A study on the question of parking is stated in the campus of Beijing Aerospace University. In recent years, attention has been paid to increasing car ownership. In addition, it is seen that the university employees choose the location far from the campus. It is stated that the problem of parking increased with increasing car ownership. There is a shortage of parking on the campus and suggestions are made. Examples of on-campus transport modeling are US universities' on-campus parking and traffic modeling. In-campus zones were determined and a model was established with PTV Visum program.

In this study, it is aimed to determine the social space usage and the access behaviors of the students by using the survey method in the fields of Koç University Sarıyer Campus (urban campus), Bahçeşehir University Beşiktaş Campus (city university), Yıldız Technical University Yıldız Central Campus (urban campus). A study was conducted.

In order to measure the travel behavior of the campus users at the Middle East Technical University Ankara campus, instead of the traditional survey method, the vehicle identification system (RFID) was used in 
the campus entrance and exits. The studies examined provide recommendations and recommendations for university campuses. Studies aim to reduce the use of alternative modes of transport and the reduction of private vehicle use. One study focuses on problems in on-campus spaces while other studies evaluate the whole city. The scope of the research was established in 1966 as Ankara State Engineering and Architecture Academy and in 1982 it was the Maltepe Campus of Gazi University.

One-to-one survey is done by traditional survey method and travel analysis is measured. In this context, a total of 274 persons were interviewed by 28 interviewers, including students, academic and administrative staff, in the Maltepe Campus of Gazi University between 17.12.2018 and 23.12.2018. Within the scope of the survey study, the users of the campus surveyed; questions such as gender, age, education department / study department, vehicle ownership status, car park preference, type of transportation used, duration of travel were asked. The results of the survey were converted into statistical and graphical expressions and the 2038 Ankara Transportation Master Plan was compared with the numerical data of the whole city for transportation and travel behaviors.

Of the total 274 people surveyed, $77 \%$ were students, $7.4 \%$ were academic staff, $4.4 \%$ were administrative staff and $10.9 \%$ were visitors. It is seen that a large part of the surveys came from Çankaya and Yenimahalle districts. At least, it is seen that there are Kazan and Ulus districts. The data obtained from the survey study were evaluated under 4 (four) headings, including vehicle ownership status, cam-pus car park preference preference, type of transportation used to the campus and time to reach campus, interpreted in the context of 2038 Ankara Transportation Master Plan data. While the vehicle ownership of the surveyed campus users is examined, it is stated that there is $19 \%$ of the vehicles. The low level of vehicle ownership reveals that public transport or alternative transport types are used in the campus. The low level of private vehicle use is a positive development both for the environment and for on-campus and off-road traffic.

According to the data of the Ankara Transportation Master Plan household car ownership, it is stated that $55.4 \%$ of the residents in Ankara have stone and $44.4 \%$ do not have a stone. With the study conducted in Maltepe campus of Gazi University, vehicle ownership status in AUAP is 
different. In the study conducted in the University, while the ownership of vehicles is low, the ownership of vehicles in AUAP data is high. The fact that the majority of university campus users are students is effective in decreasing the vehicle ownership rate.

It is seen that the car park preferences of the campus users participating in the survey are very close to each other. It is seen that the car park in the campus is the most preferred car park. It is seen that the majority of users parked their vehicles outside the campus when the priority of the parking lots is examined. The fact that student vehicles are not included in the campus triggers parking outside the campus.

2038 Ankara Transportation Master Plan vehicle park location preference is examined in Ankara; $47.5 \%$ of them use Road Parking, 36.2\% Parking and $16.3 \%$ Parking garages. The university is in parallel with the results of the study. In the campus area study, off-campus parking and offcampus parking are the most preferred car park areas. Inadequate, inaccessible and unresponsive safety problems in car parks reduce the preference of open car parks. When the types of transportation used to the campus are examined, it is seen that the most preferred modes are Bus, Ankaray, Dolmus, Metro, Yaya, respectively. The least preferred transportation types are Bike, Suburban and Taxi respectively.

2038 Ankara Transportation Master Plan When the distribution of household transportation type is examined, they prefer pedestrian journey with $27,91 \%$. In public transport, buses with a maximum of $21.67 \%$ are preferred. When the AUAP and University campus field study data are examined, it is similar to the type of transportation used in trips. The fact that the rail system does not provide service throughout the province in Ankara increases the use of buses and minibuses.

When the surveyed campus users' time to reach the campus is examined; $36 \%$ of the campus is $16-30$ minutes, $25 \%$ is $31-45$ minutes to campus, $17 \%$ is $46-60$ minutes to campus, $16 \%$ is $0-15$ minutes to campus and $5 \%$ is on campus. The duration of reaching the campus is 61 minutes or more.

Ankara is a 45-minute city. As a matter of fact, when the graph is examined, it is seen that nearly $75 \%$ of all journeys are under 45 minutes. When AUAP and University campus field study data are analyzed, travel times are parallel. Access to the campus is less than 45 minutes. According to the answers obtained from the 4 (four) questions directed to the users 
of the campus compared with the research results of the AUAP household; It is seen that the car parking place preference, the type of transportation used and the travel time are in parallel.

Vehicle Ownership Status: It differs in the university survey study with AUAP. The fact that a significant portion of the campus users are students decreases their car ownership.

Vehicle Parking Location: A large number of campus users come to the campus by means of their vehicles. According to the data of AUAP households, it is seen that a large part of the residents of Ankara use road parking. It can be said that the car parks on the road are due to insufficient open and closed car parks. The fact that the staff does not receive external vehicles increases the off-campus parking.

Type of Transportation: When the types of transportation used are examined, it is seen that the data of the AUAP household data and the campus survey study overlap. In short distances in Ankara people are reported to travel more on foot. In the public transportation, most of the wheels are preferred. The fact that the existing rail network does not reach the whole city brings forward the transportation of buses and minibuses and is more preferred. The university campus has similar behavior with Ankara, but it is differentiated by the use of rail systems.

It is observed that a university campus in the city center (Gazi University Maltepe Campus) and the general travel characteristics of Ankara city are similar. The problem of parking along the road in the city of Ankara is also seen in the campus park. On-road parking arrangements can be solved for the problem of parking along the road and off-campus parking. A separate parking area should be arranged for the student parking lot and the parking lot should be arranged again. To prevent disruptions in traffic, to avoid the problem of parking and environmental pollution on the campus should encourage the use of public transport instead of private vehicles. Systems such as dir Continue parking uygulan should be implemented. In this context, on-campus parking charges can be used to reduce the use of special vehicles. Findings, problems and suggestions The Gazi University Maltepe Campus is thought to be an important step in preventing the current situation of transportation and access problems in the future. 


\section{Kaynakça / References}

Altıntaşı, O., ve Yaman, H. T. (2016). Orta Doğu Teknik Üniversitesi yerleşkesindeki düzenli özel araç kullananların karakteristiklerinin değerlendirilmesinde RFID verisi kullanımı. Pamukkale Üniversitesi Mühendislik Bilimleri Dergisi, 22(3), 171-177.

Arap, S. K. (2007). Türkiye'de üniversitelere ilişkin politikalar ve üniversitelerin kuruluş yeri seçimi. Yayınlanmamış Doktora Tezi, İnönü Üniversitesi Sosyal Bilimler Enstitüsü, Malatya.

Asadi-Shekari, Z., Moeinaddini, M., ve Shah, M. Z. (2014). A pedestrian level of service method for evaluating and promoting walking facilities on campus streets. Land Use Policy, 38, 175-193.

Ataünal, A. (1994). 21. yüzyıla girerken eğitim. Hacettepe Üniversitesi Eğitim Fakültesi Dergisi, 10(10), 111-116.

Babalik-Sutcliffe, E. (2013). Urban form and sustainable transport: Lessons from the Ankara case. International Journal of Sustainable Transportation, 7(5), 416-430.

Balsas, C. J. (2003). Sustainable transportation planning on college campuses. Transport Policy, 10(1), 35-49.

Bustillos, B. I., Shelton, J., ve Chiu, Y. C. (2011). Urban university campus transportation and parking planning through a dynamic traffic simulation and assignment approach. Transportation planning and technology, 34(2), 177-197.

Erçevik, B. (2008). Üniversitelerde sosyal mekan kullanımlarının incelenmesi: kent üniversitesi, kent içi ve kent dışı kampüsler. Yayımlanmamış üksek Lisans Tezi, Yıldız Teknik Üniversitesi, İstanbul.

Fernandes, P., Sousa, C., Macedo, J. ve Coelho, M. C. (2019). How to evaluate the extent of mobility strategies in a university campus: An integrated analysis of impacts. International Journal of Sustainable Transportation, 1-17. doi: 10.1080/15568318.2018.1531183

Gazi Üniversitesi KUTEM. (2014). Ankara UAP Hane Halkı Araştırması Sonuçları, Ankara.

Gazi Üniversitesi KUTEM. (2014). Ankara UAP Otopark Etüdü ve Anketi, Ankara.

Gazi Üniversitesi KUTEM. (2014). Ankara UAP Yaya Etüdü ve Anketi, Ankara. 
Göçer, Ö. ve Göçer, K. (2019). The effects of transportation modes on campus use: A case study of a suburban campus. Case Studies on Transport Policy, 7(1), 37-47.

Kös, M. (2015). Kentiçi Ulaşım Problemlerine Alternatif Entegre Bisiklet Ulaşımı Planlaması, Doctoral dissertation, Fen Bilimleri Enstitüsü, İstanbul Teknik Üniversitesi, İstanbul.

Lapa, T. Y., ve Ardahan, F. (2009). Akdeniz üniversitesi öğrencilerinin serbest zaman etkinliklerine katilim nedenleri ve değerlendirme biçimleri. Spor Bilimleri Dergisi, 20(4), 132-144.

Miralles-Guasch, C., ve Domene, E. (2010). Sustainable transport challenges in a suburban university: The case of the Autonomous University of Barcelona. Transport policy, 17(6), 454-463.

Önder, H. G., ve Kaplan, H. (2017). Ankara' da park et-devam et sisteminin modellenmesi ile yolculuk değişimine bağlı emisyon azaltımının ölçülmesi. Gazi Üniversitesi Fen Bilimleri Dergisi Part C: Tasarım ve Teknoloji, 5(1), 139-152.

Önder, H.G., Akdemir, F. (2019). Türkiye'deki kentiçi raylı toplu taşıma sistemlerinin ulaşım ana planları bağlamında değerlendirilmesi, Demiryolu Mühendisliği, 10, 23-37.

Paul K. Hatt, Albert J. Reiss, Jr. (2002). Kentsel yerleşimlerin tarihi, 20. Yüzyıl Kenti, (Çev. A. Alkan, B. Duru.). Ankara: İmge Yayınevi.

Shang, H., Wenji, L. I. N., ve Huang, H. (2007). Empirical study of parking problem on university campus. Journal of Transportation Systems Engineering and Information Technology, 7(2), 135-140.

Süt, N. İ., Hamurcu, M., ve Eren, T. (2019). Kampüste yeşil ulaşım uygulaması: Ring araçlarının seçimi için bir karar verme süreci. Gazi Mühendislik Bilimleri Dergisi (GMBD), 5(1), 9-21.

\section{Kaynakça Bilgisi / Citation Information}

Ulvi, H. (2019). Üniversite yerleşkesi için yolculuk davranış analizi: Gazi Üniversitesi Maltepe yerleşkesi örneği. OPUS-Uluslararası Toplum Araştırmaları Dergisi, 11(18), 1566-1588. DOI: 10.26466/opus.559415 